\title{
An Assessment of Antidepressant and Antioxidant Activities of Bifidobacterium Infantis in rats
}

\author{
Hosam Abdel-Fattah Elshebiny ${ }^{1}$, Hala Mohamed Abu-Shady ${ }^{2}$, Dalia Abd El Moneim Mahmoud ${ }^{3}$ and \\ Shaimaa Basyouni El-Abd ${ }^{2 *}$ \\ ${ }^{1}$ Poison Control Center, Ain Shams University Hospitals, Cairo, Egypt, \\ ${ }^{2}$ Department of Microbiology, Faculty of Science, Ain Shams University, Cairo, Egypt, \\ ${ }^{3}$ Neuropsychiatry Department, Faculty of Medicine, Ain Shams University, Cairo, Egypt
}

\section{ARTICLE INFO}

Article history:

Received 26 September 2017

Accepted 20 November 2017

Keywords:

Bifidobacterium infantis;

Depression;

Forced swim test;

Antioxidants.

\begin{abstract}
A B S T R A C T
An influence of gut microbiota on behavior is becoming increasingly evident, Bifidobacterium infantis is a member of the Bifidobacteria family, a strain of bacteria that is normally found in the human intestines, they can affect tryptophan metabolism. Manipulation of tryptophan levels, acutely or chronically, by depletion or supplementation, is an experimental procedure for modifying peripheral and central serotonin levels producing a possibility that alterations in the gut may be important in the pathophysiology of human central nervous system disorders like depression. The present study was carried out to evaluate the antidepressant and antioxidant activity of Bifidobacterium infantis on rats that were exposed to forced swim test to stimulate depression-like state. The effect was assessed by whole blood serotonin, serum malondialdehyde (MDA), serum nitric oxide (NO) and glutathione peroxidase (GPx) measurements. Rats were divided into three groups (20rats/group) control group (not exposed to forced swim test), depressed group (exposed daily to FST for 2 weeks) and prophylactic group (received a dose of $1 \times 10^{12}$ of Bifidobacterium infantis via oral gavage route every day and $2 \mathrm{hrs}$ later exposed to forced swim test) for 2 weeks. Significant differences were found between depressed and both the control and prophylactic group as regard all measured parameters (whole blood serotonin, MDA, NO and GPx). When comparing bifidobacteria-treated rats to controls, there was no significant difference in all parameters except GPx, where there was a significant increase. This data provides encouraging evidence in support of the hypothesis that this probiotic may possess antidepressant and antioxidant properties.
\end{abstract}

\section{Introduction}

Major depressive disorder that is often called simply depression refers to a psychological state featured by a low mood and a lack of activity ; this state that can affect cognition, behavior, feelings, and one's overall sense of well-being ${ }^{[1]}$.

Several mechanisms play role in the pathogenesis of depression. It may be caused by abnormalities in metabolism of neurotransmitters (e.g., serotonin and dopamine) that are consequently affected by the synthesis of their precursor tryptophan ${ }^{[2]}$. Serotonin (5HT), the most important of the monoamines /neurotransmitters involved in depression pathology, is decreased in depression-related brain regions during depressive episodes ${ }^{[3]}$.

* Corresponding author.

E-mail address: beautifulmind-86@hotmail.com
}

There are several references indicating that reactive oxygen species (ROS) inducing neuronal damage have an important role in the pathophysiology of depression. Studies have demonstrated the abnormality in oxidative product levels in the peripheral blood, red blood cells (RBC), mononuclear cells, urine, cerebrospinal fluid and postmortem brains in depressed patients. Antioxidant system disturbance in peripheral blood has also been reported ${ }^{[4]}$. Because ROS have short half-lives, most studies measured the products of oxidative damage. Malondialdehyde (MDA) is the most studied product of lipid peroxidation. Numerous studies reported increasing levels of MDA and other products of lipid peroxidation in depressed patients. Nitric oxide (NO) is responsible for the formation of many end products involved in oxidative stress and increased plasma NO levels have also been reported in depressive patients. The major 
antioxidative defenses include both enzymatic and nonenzymatic antioxidants. The levels of enzymatic antioxidants like GPx are altered in major depressive disorder patients ${ }^{[5]}$.

Brain is vulnerable to oxidative stress because it has a high oxygen demand, which constitutes $20 \%$ of the body oxygen consumption, due to high levels of polyunsaturated fatty acids which are found in the brain cell membranes reacting as substrates for lipid peroxidation ${ }^{[6]}$.

Many treatment strategies have been used to fight depression, including pharmaceuticals such as selective serotonin reuptake inhibitors (SSRIs).Also, probiotic treatments may provide potential treatments and preventative measures for depressive disorders ${ }^{[7]}$.

The term probiotic is derived from the Greek language, meaning "for life" ${ }^{[8]}$. The food and agriculture organization of the United Nations (FAO) and world health organization (WHO) defined probiotics as live organism which, when consumed in adequate amounts as part of food, confer a health benefit on the host ${ }^{[9]}$.

Probiotics are broadly classified into two genus Lactobacillus and Bifidobacterium ${ }^{[10]}$. Bifidobacteria are one of the predominant bacterial groups of the human intestinal microbiota and have important functional properties making them interesting for the food and dairy industries ${ }^{[11]}$. Their predominance during neonatal development suggests that bifidobacteria play a major role in development and function of the immune and digestive systems ${ }^{[12]}$.

The objective of this study was to investigate the potential antidepressant and antioxidant properties of the probiotic, Bifidobacterium infantis. This was achieved by induction of depression-like state by repeated forced swim test for rats in which the animals were subjected to short daily swims for $10 \mathrm{~min}$ and treated with a Bifidobacterium infantis as a prophylactic treatment.

Materials and methods

\section{Bifidobacterium infantis administration}

Bifidobacterium infantis (purchased from metabolics Ltd., Eastcott, Devizes, England) was administered by dissolving a powdered preparation, containing a dose of $1 \mathrm{X} 10^{12}$ live bacterial cells (each gram of Bifidobacterium infantis powder supplies 10 billion colony forming unit (CFU), in $100 \mathrm{ml}$ of the rats drinking water and administrated by oral route gavage [13].

\section{Experimental animals:}

60 Male Sprague Dawley rats weighing 200-250 g were obtained from the Vaccine and Immunization Authority (Helwan, Cairo, Egypt) and bred in the animal housing facility, Faculty of Medicine, Ain Shams University. Rats were randomly divided into three groups:

Group I: control group: 20 rats that were not exposed to FST.

Group II: depressed group: 20 rats that were exposed daily to FST for 14 days to cause behavioral chronic depression.

Group III: prophylactic group: 20 rats that were exposed daily to FST for 14 days after receiving a dose of Bifidobacterium infantis $1 \times 10^{12}$ via oral rote gavage.

\section{Depression induced by FST}

The FST ${ }^{[14]}$ was done by immersing rats individually in a $60 \times 50 \times 40 \mathrm{~cm} \quad(\mathrm{~L} \times \mathrm{W} \times \mathrm{H})$ basin container filled with water $\left(23-25^{\circ} \mathrm{C}\right)$ from which it could not escape out for 10 min for 14 days to cause behavioral depression ${ }^{[15]}$.

\section{Sample collection:}

According to the method of Coccheto et al ${ }^{[16]}$ blood samples were withdrawn from the retro-orbital vein of each animal, under light anesthesia by diethyl ether. Samples were stored at $-80^{\circ} \mathrm{C}$ to be thawed only once on demand for determination of the following parameters:

\section{I) Determination of serotonin}

According to the method of Geeraerts et al ${ }^{[17]}$ (a simple routine quantitative fluorometric method for determination of serotonin). $1 \mathrm{ml}$ of blood is added to 0.1 $\mathrm{ml}$ of 3\% solution of ascorbic acid in saturated EDTA $\mathrm{Na}_{2}(15 \mathrm{~g} / 100 \mathrm{ml})$ and frozen immediately and kept at -18 until determination. Before determination of serotonin the blood is unfrozen and $2.5 \mathrm{ml}$ of water is added to ensure complete hemolysis, after $10 \mathrm{~min} 1 \mathrm{ml}$ of $10 \% \mathrm{ZnSO}_{4}$ and $0.5 \mathrm{ml} 1 \mathrm{~N} \mathrm{NaOH}$ are added to precipitate the proteins and mix well. The suspension is centrifuged for $5 \mathrm{~min}$ with Jouan centrifuge at rate of $3000 \mathrm{rpm}$. to $1 \mathrm{ml}$ of clear supernatant, $0.3 \mathrm{ml}$ of $12 \mathrm{~N}$ $\mathrm{HCl}$ (containing $5 \mathrm{mg}$ ascorbic acid per $10 \mathrm{ml} \mathrm{HCl}$ ) is added, this is done just before measuring of sample with spectrofotofluorometer at $540 \mathrm{~nm}$ after excitation at 295 $\mathrm{nm}$. The results were expressed as ng of serotonin $/ \mathrm{mL}$ blood.0.1 N HCl is used as blank and serotonincreatinine sulfate used as standard solution (SigmaAldrich St. Louis, MO, USA).

\section{II) Determination of Malondialdehyde}

According to the method of Uchiyama \& Mihara ${ }^{[18]}$ (Determination of Malonaldehyde Precursor in Tissues by Thiobarbituric Acid Test). Thiobarbituric acid reacted with the breakdown products of peroxidized lipids (e.g. malonyldialdehyde) the resultant pink colored product is extracted by $n$-butanol and the absorbance is determined spectrophotometrically at $535 \mathrm{~nm}$. The results were expressed as nmol of malonyldialdehyde (MDA)/mL serum. Malonaldehyde bis (dimethyl acetal) (Sigma aldrich) was used as an external standard.

\section{III) Determination of serum Nitric Oxide (NO)}

According to the method of Boris \& Bories (Nitrate determination in biological fluids by an enzymatic onestep assay with nitrate reductase). Serum nitrate was determined using one step enzymatic assay based on the reduction of nitrate by nitrate reductase in the presence of $\beta$-NADPH and flavin adenine dinucleotide (FAD). Serum samples $(200 \mu \mathrm{L})$ were incubated with 57mMpotassium phosphate buffer (PBS, pH 7.6), 0.005 $\mathrm{mM}$ flavin adenine dinucleotide (FAD), $0.2 \mathrm{mM} \beta$ nicotinamide adenine dinucleotide phosphate reduced form $(\beta$-NADPH), $10 \mathrm{mM}$ sodium nitrate and $0.013-$ 0.025 unit nitrate reductase for $30 \mathrm{~min}$ at room temperature. The control sample was analyzed daily with an exogenous standard (sodium nitrate). The concomitant 
oxidation of the co-enzyme $\beta$-NADPH was monitored by the decrease in the absorbance at $340 \mathrm{~nm}$. FAD was used as a supplementary electron carrier. Nitrate reductase, FAD and $\beta$-NADPH were purchased from Sigma Aldrich (USA).

IV) Determination of glutathione peroxidase in erythrocytes.

According to the method Paglia \& Valentine (Studies on the quantitative and qualitative characterization of erythrocyte glutathione peroxidase). $0.01 \mathrm{ml}$ of blood were added to $1.0 \mathrm{ml}$ of phosphate buffer ( $\mathrm{PH} 7.0$ ) and $0.1 \mathrm{ml}$ of $\mathrm{NADPH}$ then add $\mathrm{H}_{2} \mathrm{O}_{2}$ (oxidizing agent) which oxidize NADPH to $\mathrm{NADP}^{+}$. This oxidation is accompanied by a decrease in absorbance at $340 \mathrm{~nm}$ providing a spectrophotometric means for monitoring GPx enzyme activity.

\section{Statistical analysis}

In the present study, all data were statistically analyzed by SPSS Software version 21. Results were expressed as mean and standard deviation. Statistical analysis was performed using Student's unpaired t-test. P values less than 0.05 were considered significant.

\section{Results}

The mean level of whole blood serotonin in depressed group (group II) was significantly decreased when compared with control group (group I), (Table 1).

Oral administration of Bifidobacterium infantis (group III) showed a significant increase $(\mathrm{p}<0.001)$ in whole blood serotonin level compared to depressed group (group II) .But, there was no significant difference in whole blood serotonin level between prophylactic group (group III) and control group (group I), (Table 1).

The mean level of MDA in depressed group (group II) was significantly higher $(\mathrm{p}<0.01)$ when compared to control group (group I), (Table 1).

On the other hand, oral administration of Bifidobacterium infantis (group III) showed a significant decrease $(\mathrm{p}<0.001)$ in MDA serum level compared to depressed group (group II). But, oral administration of Bifidobacterium infantis has no significant change in serum MDA level when compared to control.

The mean serum level of NO in depressed group (group II) was significantly increased $(\mathrm{p}<0.001)$ compared to control group (group I), (Table 1).

On the other hand, oral administration of Bifidobacterium infantis (group III) showed a significant decrease $(\mathrm{p}<0.001)$ in serum nitric oxide level compared to depressed group (group II) (Table 1). Finally, there was no significant change between mean values of prophylactic group (group III) and control group (group I)

The mean whole blood GPx in depressed group (group II) was significantly decreased $(\mathrm{p}<0.01)$ compared to control group (group I). (Table 1) Oral administration of Bifidobacterium infantis (group III) showed a highly significant increase ( $p<0.001)$ in whole blood glutathione peroxidase level compared to depressed group (group II). Also, oral administration of Bifidobacterium infantis (group III) showed a significant increase ( $\mathrm{p}<0.001)$ in whole blood glutathione peroxidase level compared to control group (Table 1).

Table 1: The mean value of different measured paremeters in all studied groups.

\begin{tabular}{|c|c|c|c|c|}
\hline \multicolumn{2}{|c|}{ Parameters Groups } & $\begin{array}{l}\text { Group (I) } \\
\text { Control }\end{array}$ & $\begin{array}{l}\text { Group (II) } \\
\text { Depressed }\end{array}$ & $\begin{array}{l}\text { Group (III) } \\
\text { Prophylactic }\end{array}$ \\
\hline \multirow{2}{*}{$\begin{array}{l}\text { Serotonin } \\
(\mathrm{ng} / \mathrm{ml})\end{array}$} & $\operatorname{Mean} \pm$ SD & $1248.00 \pm 103.46$ & $482.50 \pm 68.51$ & $1193.25 \pm 139.90$ \\
\hline & $\begin{array}{l}\mathbf{P} \text { value } \\
\mathbf{P}^{*} \text { value }\end{array}$ & & $\begin{array}{l}0.001 \\
0.001\end{array}$ & N.S \\
\hline \multirow{2}{*}{$\begin{array}{l}\text { MDA } \\
(\mathbf{n m o l} / \mathbf{m l})\end{array}$} & Mean \pm SD & $3.70 \pm 0.43$ & $7.21 \pm 1.25$ & $3.74 \pm 0.46$ \\
\hline & $\begin{array}{l}\text { P value } \\
\text { P* value }\end{array}$ & & $\begin{array}{l}0.001 \\
0.001\end{array}$ & N.S \\
\hline \multirow{2}{*}{$\begin{array}{l}\text { Nitric oxide } \\
\text { (nmol/l) }\end{array}$} & Mean \pm SD & $30.2 \pm 8.14$ & $55.00 \pm 7.94$ & $27.95 \pm 7.9$ \\
\hline & $\begin{array}{l}\mathbf{P} \text { value } \\
\mathbf{P}^{*} \text { value }\end{array}$ & & $\begin{array}{l}0.001 \\
0.001\end{array}$ & N.S \\
\hline \multirow{2}{*}{ GPx $(\mathbf{U} / \mathbf{m l})$} & Mean \pm SD & $228.35 \pm 15.66$ & $174.70 \pm 10.36$ & $277.40 \pm 9.21$ \\
\hline & $\begin{array}{l}\text { P value } \\
\text { P* value }\end{array}$ & & $\begin{array}{l}0.001 \\
0.001\end{array}$ & 0.001 \\
\hline
\end{tabular}

Data are expressed as mean \pm SD.

$\mathrm{P}$ value Statistical significant difference of group II and group III when compared to control $<0.001$. $\mathrm{P}^{*}$ value

Statistical significant difference between group II and group III $<0.001$. 


\section{Discussion}

According to the World Health Organization (WHO), depression is currently the fourth leading cause of the global burden of disease; it is predicted that depression will be ranked second by 2020 . The WHO has predicted that, by 2030, depression will account for the highest level of disability attributable to any physical or mental disorder worldwide ${ }^{[21]}$.

Animal models of depression play an important role in the screening and evaluation of antidepressants ${ }^{[22]}$. The state of immobility in the FST is reported to mimic the symptoms of depression in humans and can be reversed by treatment with antidepressant drugs ${ }^{[23]}$. In FST, rats are forced to swim in restricted space from which they cannot escape. This induces a state of behavioral despair in animals, which is claimed to reproduce a condition similar to depression in human ${ }^{[24]}$.

Whole blood serotonin is an easily obtained blood measure. It is thought to be a good estimate of platelet serotonin content ${ }^{25]}$. Neurons and platelets display structural and functional similarities, so that the latter have been proposed as a peripheral model of central functions. In particular, in blood more than $99 \%$ of serotonin $(5-\mathrm{HT})$ is contained in platelet, so that one could consider changes in 5-HT levels in platelets as a mirror of changes in central 5- $\mathrm{HT}^{[26]}$.

In the present study, the whole blood serotonin in depressed group (group II) was significantly decreased when compared with control group (group I). It has been hypothesized that major depression is due to a deficiency of available serotonin or sensitivity of key serotonin receptors in relevant brain regions ${ }^{[27]}$.

Liu et al ${ }^{[28]}$ similarly reported significantly decreased levels of the whole blood serotonin in depressed group of adult male rats that were submitted to a modified FST. Also, Maurer-Spurej ${ }^{[29]}$ reported significantly lower platelet serotonin levels in women with postpartum depression.

On the other hand, Schins et al ${ }^{[30]}$ reported the association of depression with elevated whole blood serotonin in a small case-control study of 25 depressed post myocardial infraction (MI) patients.

Administration of Bifidobacterium infantis in prophylactic group (group III) has a significant increase in whole blood serotonin level when compared with depressed rats (group II). Similar results have been obtained by Al-Asmakh et al [31] who reported that administration of the commensal bacteria, Bifidobacteria infantis, increased the plasma concentration of tryptophan, suggesting that the normal microbiota can influence the precursor pool for serotonin (5-HT) as serotonin synthesis in the brain is crucially dependent on the availability of tryptophan.

Tryptophan has two pathways: 1) the kynurenine (KYN) pathway and 2) the serotonin (5-HT) pathway. The mechanism by which Bifidobacterium infantis may produce antidepressant like effect may be associated with the suppression of IFN- $\gamma$ production. IFN- $\gamma$ has been shown to be a potent stimulus in the activation of indoleamine (2,3)-dioxygenase (IDO), the enzyme involved in the conversion of tryptophan to kynurenine and is considered to have the greatest effect on the progression of depression. When IDO is inhibited by the suppression of IFN- $\gamma$, the kynurenine: tryptophan ratio decreased and the other pathway serotonin: tryptophan is enhanced ${ }^{[32,33]}$.

Major depression is also associated with elevated levels of proinflammatory cytokines, which have been shown to lead to oxidative stress by producing reactive oxygen species and nitric oxide ${ }^{[34,55]}$. Products of oxidative stress represent important parameters for measuring and predicting of depression status as well as for determining effectiveness of administrated antidepressants ${ }^{[36]}$.

Lipid peroxidation is one of main manifestations of oxidative damage induced by the free radicals produced during various conditions ${ }^{[37]}$. Malondialdehyde (MDA) is the principal and most studied product of polyunsaturated fatty acid peroxidation ${ }^{[38]}$. Nitric oxide is generated by inflammatory cytokines due to the action of inducible nitric oxide (iNOS) ${ }^{[39]}$.

The results of the present study provide evidence of an increased oxidative stress status in depression as shown by statistically significant elevation in serum MDA in depressed rats when compared with control group. Similar results were reported in depressive patients ${ }^{[40,41]}$. In prophylactic group (group III), the MDA levels of the rats were significantly lower than those of the depressed ones. Another study found a significant decrease in MDA levels in colonic tissues after administration of Bifidobacterium infantis ${ }^{[42]}$.

The present study showed also a significant increase in nitrogen-reactive species with depression. The NO levels of depressed rats were found to be significantly higher than those of controls.

Similar demonstrates were found by other studies which found significantly increased nitric oxide metabolites when compared with control group ${ }^{[43,44]}$.

Nitric oxide levels were significantly decreased in prophylactic group (group III) when compared to depressed group (group II). Most importantly, the NO levels of prophylactic group (group III) were similar to those of the control group which shows the success of antidepressant therapy in balancing oxidative stress. Similar results found that administration of Bifidobacterium infantis significantly decreased nitric oxide level and also reported that administration of Bifidobacterium infantis significantly decreased expression of inducible nitric oxide synthase (a marker of inflammation) ${ }^{[45]}$. Wang et al ${ }^{[46]}$ reported that inducible nitric oxide synthase also made contributions to the mechanism of depression.

Failure of antioxidant defense may lead to oxidative damage and the initiation of lipid peroxidation. In the current study there was a significant decrease in whole blood glutathione peroxidase activity in rats with depression (group II) when compared to control group, suggesting a disturbance in pro-oxidants and antioxidant balance in depression ${ }^{[47]}$. 
The same was reported by other studies, which found significantly decreased whole blood glutathione peroxidase levels in depressive patients and suggested that depression was accompanied by decreased activities of main antioxidant enzyme activity including glutathione peroxidase ${ }^{[48,49]}$.

In the current study, administration of Bifidobacterium infantis on a daily basis significantly increases whole blood glutathione peroxidase level when compared to control group. This can be explained by the fact that repeated stress on a daily basis may impair the antioxidant defenses in the body leading to oxidative damage by changing the balance between oxidant and antioxidant factors. The increased levels of oxidative damage could be due to the increased concentration of glucocorticoids [50]. Sudo et al [51] found that Bifidobacterium infantis play a protective role against the elevated plasma glucocorticoid levels.

\section{References}

1) Murillo-Zamora, E., Macías-de la Torre, A. A. and Higareda-Almaraz, M. A. (2015). Depression prevalence among end stage renal disease patients in maintenance hemodialysis. Revista medica del Instituto Mexicano del Seguro Social, 54(4):429433.

2) Vaváková, M., Ďuračková, Z. and Trebatická, J. (2015). Markers of oxidative stress and neuroprogression in depression disorder. Oxidative medicine and cellular longevity, 2015.

3) Gałecki, P., Szemraj, J., Bieńkiewicz, M., Florkowski, A. and Galecka, E. (2009). Lipid peroxidation and antioxidant protection in patients during acute depressive episodes and in remission after fluoxetine treatment. Pharmacological reports, 61(3):436-447.

4) Liu, M. Y., Ren, Y. P., Wei, W. L., Tian, G. X. and Li, G. (2015). Changes of serotonin (5-HT), 5HT2A receptor, and 5-HT transporter in the Sprague-Dawley rats of depression, myocardial infarction and myocardial infarction co-exist with depression. Chinese medical journal, 128(14):1905.

5) Cimen, B., Gumus, C. B., Cetin, I., Ozsoy, S., Aydin, M. and Cimen, L. (2015). The effects of escitalopram treatment on oxidative/antioxidative parameters in patients with depression. Klinik Psikofarmakoloji Bülteni-Bulletin of Clinical Psychopharmacology, 25(3):272-279.

6) Wang, X. and Michaelis, E. K. (2010). Selective neuronal vulnerability to oxidative stress in the brain. Frontiers in aging neuroscience; 2:12.

7) Slyepchenko, A., F Carvalho, A., S Cha, D., Kasper, S. and S McIntyre, R. (2014): Gut emotions-mechanisms of action of probiotics as novel therapeutic targets for depression and anxiety disorders. CNS \& Neurological Disorders-Drug Targets (Formerly Current Drug Targets-CNS \& Neurological Disorders); 13(10):1770-1786.

8) Pavithra, R. S. and Lakshmisree, S. (2015). Probiotics-A Miracle in Periodontal Therapy.
Scholars Journal of Dental Sciences. Sci., 2(4):265269.

9) Food and agriculture organization of the United Nations and World Health Organization (FAO/WHO). Probiotics in food-health and nutritional properties and guidelines for evaluation. FAO food and nutrition paper. Rome, Italy: Food and Agriculture Organization of the United Nation and World Health Organization. paper 85; ISBN 925-105513-0.

10) Bose, B. B. (2013). Probiotics-Promotes Periodontal Health?-An Insight. International Journal of Dental Sciences and Research; vol. 1(3):67-70.

11) Grimm, V., Westermann, C. and Riedel, C. U. (2014). Bifidobacteria-host interactions - an update on colonisation factors. BioMed research international; 2014:1-10.

12) Matamoros, S., Gras-Leguen, C., Le Vacon, F., Potel, G. and de La Cochetiere, M. F. (2013). Development of intestinal microbiota in infants and its impact on health. Trends in microbiology; vol. 21(4):167-173.

13) Desbonnet, L., Garrett, L., Clarke, G., Kiely, B., Cryan, J. F. and Dinan, T. G. (2010). Effects of the probiotic Bifidobacterium infantis in the maternal separation model of depression. Neuroscience; vol. 170(4):1179-1188.

14) Porsolt, R. D., Le Pichon, M. and Jalfre, M. L. (1977). Depression: a new animal model sensitive to antidepressant treatments. Nature, 266(5604):730732.

15) Lucki, I. (1997). The forced swimming test as a model for core and component behavioral effects of antidepressant drugs. Behavioural pharmacology, 8(6-7):523-532.

16) Cocchetto, D. M. and Bjornsson, T. D. (1983). Methods for vascular access and collection of body fluids from the laboratory rat. Journal of pharmaceutical sciences, 72(5), 465-492

17) Geeraerts, F., Schimpfessel, L. and Crokaert, R. (1974). A simple routine-method to preserve and determine blood serotonin. Experientia, 30(7):837837.

18) Uchiyama, M., and Mihara, M. (1978). Determination of malonaldehyde precursor in tissues by thiobarbituric acid test. Analytical biochemistry, 86(1):271-278.

19) Bories, P. N. and Bories, C. (1995). Nitrate determination in biological fluids by an enzymatic one-step assay with nitrate reductase. Clinical Chemistry, 41(6):904-907.

20) Paglia, D. E. and Valentine, W. N. (1967). Studies on the quantitative and qualitative characterization of erythrocyte glutathione peroxidase. The Journal of laboratory and clinical medicine, 70(1):158-169.

21) Muñoz, R. F. and Bunge, E. L. (2016). Prevention of depression worldwide: a wake-up call. The lancet. Psychiatry, 3(4):306. 
22) McArthur, R. and Borsini, F. (2006). Animal models of depression in drug discovery: a historical perspective. Pharmacology Biochemistry and Behavior, 84(3):436-452.

23) Renard, C. E., Dailly, E., David, D. J., Hascoet, M. and Bourin, M. (2003). Monoamine metabolism changes following the mouse forced swimming test but not the tail suspension test. Fundamental \& clinical pharmacology, 17(4):449455.

24) Willner, P. (1984). The validity of animal models of depression. Psychopharmacology, 83(1):1-16.

25) Kremer, H. P. H., Goekoop, J. G. and Van Kempen, G. M. (1990). Clinical use of the determination of serotonin in whole blood. Journal of clinical psychopharmacology, 10(2):83-87.

26) Bianchi, M., Moser, C., Lazzarini, C., Vecchiato, E. and Crespi, F. (2002). Forced swimming test and fluoxetine treatment: in vivo evidence that peripheral 5-HT in rat platelet-rich plasma mirrors cerebral extracellular 5-HT levels, whilst 5-HT in isolated platelets mirrors neuronal 5-HT changes. Experimental Brain Research, 143(2):191-197.

27) Mann, J. J., Malone, K. M., Diehl, D. J. and Perel, J. (1996). Demonstration in vivo of reduced serotonin responsivity in the brain of untreated depressed patients. The American journal of psychiatry, 153(2):174.

28) Liu, M. Y., Ren, Y. P., Wei, W. L., Tian, G. X. and Li, G. (2015). Changes of serotonin (5-HT), 5HT2A receptor, and 5-HT transporter in the Sprague-Dawley rats of depression, myocardial infarction and myocardial infarction co-exist with depression. Chinese medical journal, 128(14):1905.

29) Maurer-Spurej, E., Pittendreigh, C. and Misri, S. (2007). Platelet serotonin levels support depression scores for women with postpartum depression. Journal of psychiatry \& neuroscience: 32(1):23.

30) Schins, A., Hamulyák, K., Scharpé, S., Lousberg, R., Van Melle, J., Crijns, H. and Honig, A. (2004). Whole blood serotonin and platelet activation in depressed post-myocardial infarction patients. Life sciences, 76(6):637-650.

31) Al-Asmakh, M., Anuar, F., Zadjali, F., Rafter, J. and Pettersson, S. (2012). Gut microbial communities modulating brain development and function. Gut microbes, 3(4):366-373.

32) Miura, H., Ozaki, N., Sawada, M., Isobe, K., Ohta, T. and Nagatsu, T. (2008). A link between stress and depression: shifts in the balance between the kynurenine and serotonin pathways of tryptophan metabolism and the etiology and pathophysiology of depression. Stress, 11(3):198209.

33) Desbonnet, L., Garrett, L., Clarke, G., Kiely, B., Cryan, J. F. and Dinan, T. G. (2010). Effects of the probiotic Bifidobacterium infantis in the maternal separation model of depression. Neuroscience, 170(4):1179-1188.
34) Hou, C. C., Lin, H., Chang, C. P., Huang, W. T. and Lin, M. T. (2011). Oxidative stress and pyrogenic fever pathogenesis. European journal of pharmacology, 667(1):6-12.

35) Iborra, M., Moret, I., Rausell, F., Bastida, G., Aguas, M., Cerrillo, E. and Beltrán, B. (2011). Role of oxidative stress and antioxidant enzymes in Crohn's disease. Biochemical Society Transactions; 39(4):1102-1106.

36) Vaváková, M., Ďuračková, Z. and Trebatická, J. (2015). Markers of oxidative stress and neuroprogression in depression disorder. Oxidative medicine and cellular longevity. 2015:1-12.

37) Santamaría, A., Sanchez-Rodriguez, J., Zugasti, A., Martínez, A., Galván-Arzate, S. and SeguraPuertas, L. (2002). A venom extract from the sea anemone Bartholomea annulata produces haemolysis and lipid peroxidation in mouse erythrocytes. Toxicology, 173(3):221-228.

38) Ebrahimi-Mameghani, M., Sanaie, S., Mahmoodpoor, A. and Hamishehkar, H. (2013). Effect of a probiotic preparation (VSL\# 3) in critically ill patients: A randomized, double-blind, placebo-controlled trial (Pilot Study). Pakistan journal of medical sciences, 29(2):490.

39) Abdel-Salam, O. M., Morsy, S. M. Y. and Sleem, A. A. (2011). The effect of different antidepressant drugs on oxidative stress after lipopolysaccharide administration in mice. EXCLI journal, 10:290.

40) Bajpai, A., Verma, A. K., Srivastava, M. and Srivastava, R. (2014). Oxidative stress and major depression. Jornal of clinical and diagnostic research, 8(12):CC04-CC07.

41) Ghodake, S. R., Suryakar, A. N., Kulhalli, P. M., Padalkar, R. K. and Shaikh, A. K. (2012). A study of oxidative stress and influence of antioxidant vitamins supplementation in patients with major depression. Current Neurobiology, 3(2):107-111.

42) Osman, N., Adawi, D., Molin, G., Ahrne, S., Berggren, A. and Jeppsson, B. (2006). Bifidobacterium infantis strains with and without a combination of oligofructose and inulin (OFI) attenuate inflammation in DSS-induced colitis in rats. Bmc Gastroenterology, 6(1):1.

43) Peng, Y. L., Liu, Y. N., Liu, L., Wang, X., Jiang, C. L. and Wang, Y. X. (2012). Inducible nitric oxide synthase is involved in the modulation of depressive behaviors induced by unpredictable chronic mild stress. Journal of neuroinflammation, 9(1):75.

44) Dowlati, Y., Herrmann, N., Swardfager, W., Liu, H., Sham, L., Reim, E. K. and Lanctôt, K. L. (2010). in major A meta-analysis of cytokines depression. Biological psychiatry, 67(5):446-457.

45) Underwood, M. A., Arriola, J., Gerber, C. W., Kaveti, A., Kalanetra, K. M., Kananurak, A., Bevins, C. L., Mills, D. A. and Dvorak, B. (2014). Bifidobacterium longum subsp. infantis in experimental necrotizing enterocolitis: alterations in 
inflammation, innate immune response, and the microbiota. Pediatric research, 76(4):326-333.

46) Wang, D., An, S. C. and Zhang, X. (2008). Prevention of chronic stress-induced depression-like behavior by inducible nitric oxide inhibitor. Neuroscience letters, 433(1):59-64.

47) Gałecki, P., Szemraj, J., Bieńkiewicz, M., Florkowski, A. and Galecka, E. (2009). Lipid peroxidation and antioxidant protection in patients during acute depressive episodes and in remission after fluoxetine treatment. Pharmacological reports, 61(3):436-447.

48) Rybka, J., Kędziora-Kornatowska, K., BanaśLeżańska, P., Majsterek, I., Carvalho, L. A., Cattaneo, A., Anacker, C. and Kędziora, J. (2013). Interplay between the pro-oxidant and antioxidant systems and proinflammatory cytokine levels, in relation to iron metabolism and the erythron in depression. Free Radical Biology and Medicine, 63:187-194.
49) Maes, M., Mihaylova, I., Kubera, M., Uytterhoeven, M., Vrydags, N. and Bosmans, E. (2010). Lower whole blood glutathione peroxidase (GPX) activity in depression, but not in myalgic encephalomyelitis/chronic fatigue syndrome: another pathway that may be associated with coronary artery disease and neuroprogression in depression. Neuroendocrinology letters, 32(2):133-140.

50) Nayanatara, A. K., Nagaraja, H. S. and Anupama, B. K. (2005). The effect of repeated swimming stress on organ weights and lipid peroxidation in rats. Thai Journal of Physiological Sciences, 18(1):3-9.

51) Sudo, N., Chida, Y., Aiba, Y., Sonoda, J., Oyama, N., Yu, X. N. and Koga, Y. (2004). Postnatal microbial colonization programs the hypothalamicpituitary-adrenal system for stress response in mice. The Journal of physiology, 558(1):263-275. 